\title{
NOTITIE KIWK
}

\section{Maatregeleffectiviteit plasherstel}

Algenrespons op nutriënten-reductie in de Groote Melanen

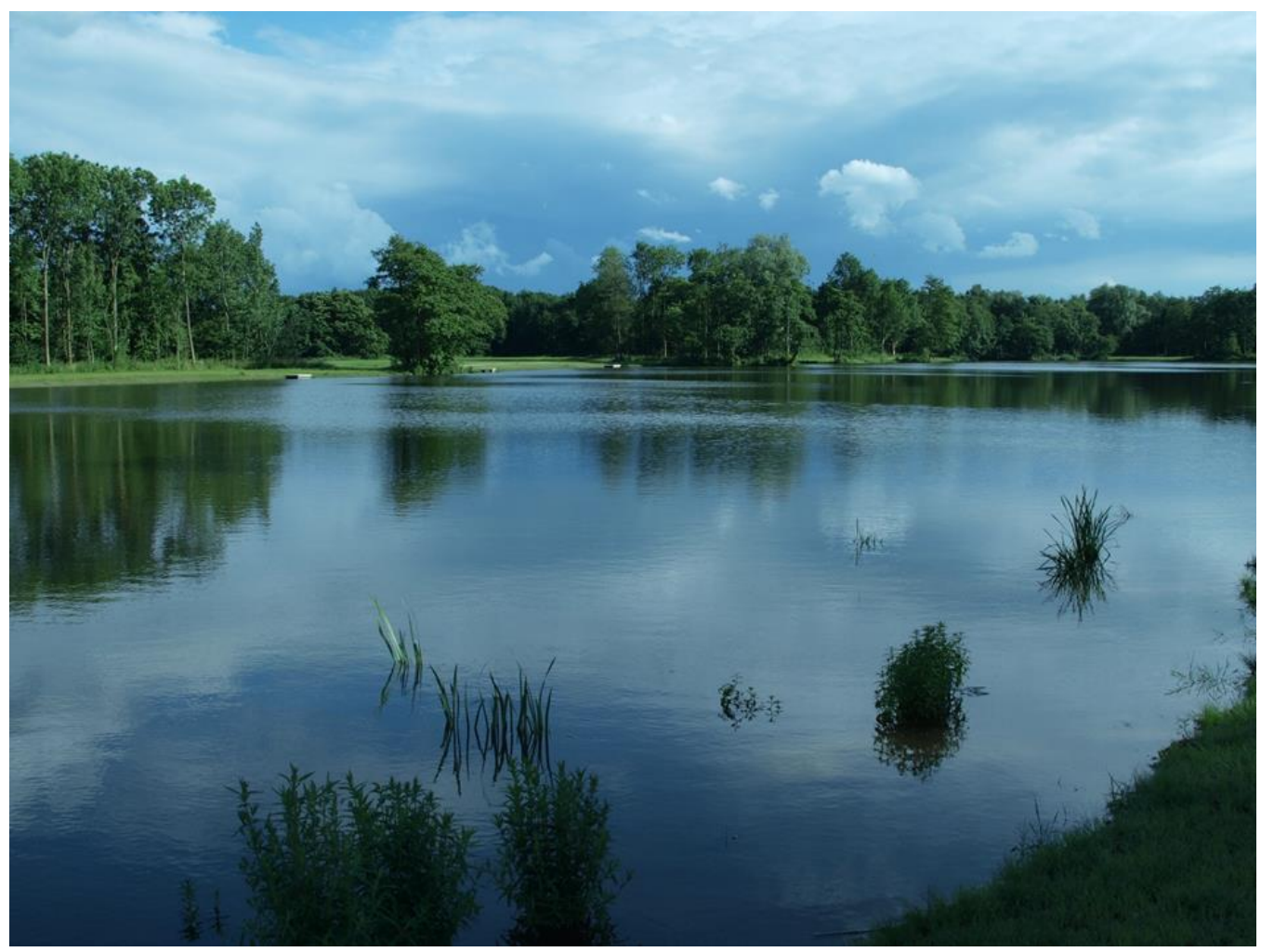

Gea van der Lee, Ralf Verdonschot, Guido Waajen en Piet Verdonschot

Zoetwaterecosystemen, Wageningen Environmental Research 


\section{Auteurs}

Gea van der Lee, Ralf Verdonschot, Guido Waajen en Piet Verdonschot (correspondentie: gea.vanderlee@wur.nl)

\section{Opdrachtgever}

Kennisimpuls waterkwaliteit (KIWK) - Waterschap de Brabantse Delta

\section{Projectgroep}

Gebruikerscommissie Kennisimpuls waterkwaliteit Systeemkennis ecologie en waterkwaliteit

\section{Wijze van citeren}

van der Lee G.H., Verdonschot R.C.M., Waajen, G. en Verdonschot P.F.M. (2021). Maatregeleffectiviteit plasherstel: Algenrespons op nutriënten-reductie in de Groote Melanen. Notitie Kennisimpuls waterkwaliteit (KIWK), Zoetwaterecosystemen, Wageningen Environmental Research, Wageningen UR, Wageningen. $13 \mathrm{pp}$.

\section{Trefwoorden}

Groote Melanen, algen, plasherstel, nutriënten

\section{Beeldmateriaal}

Guido Waajen - Waterschap de Brabantse Delta

DOI: https://doi.org/10.18174/551441

Dit project is uitgevoerd in opdracht van de Kennisimpuls waterkwaliteit (KIWK).

(c) 2021 Zoetwaterecosystemen, Wageningen Environmental Research

- Overname, verveelvoudiging of openbaarmaking van deze vitgave is toegestaan mits met duidelijke bronvermelding.

- Overname, verveelvoudiging of openbaarmaking is niet toegestaan voor commerciële doeleinden en/of geldelijk gewin.

- Overname, verveelvoudiging of openbaarmaking is niet toegestaan voor die gedeelten van deze uitgave waarvan duidelijk is dat de auteursrechten liggen bij derden en/of zijn voorbehouden.

Wageningen Environmental Research aanvaardt geen aansprakelijkheid voor eventuele schade voortvloeiend uit het gebruik van de resultaten van dit onderzoek of de toepassing van de adviezen. 


\section{Inhoud}

Inhoud 1

Samenvatting 2

1 Inleiding 3

2 Materiaal en methoden 4

2.1 Metingen 4

2.2 Taxonomische afstemming 4

2.3 Data-analyse 4

3 Resultaten 7

3.1 Algemene trends $\quad 7$

3.2 PCA ordinatie en cluster analyse 9

$\begin{array}{lll}3.3 & \text { PRC analyse } & 10\end{array}$

4 Conclusies 11

5 Literatuur $\quad 12$

6 Supplement 13 


\section{Samenvatting}

Een van de doelen van de Kennisimpuls waterkwaliteit (KIWK) is het kwantificeren van de effectiviteit van lokale maatregelen in verschillende watertypen op verschillende organismengroepen. In dit document wordt de effectiviteit van een pakket van nutriënt reducerende maatregelen op de algenrespons in de Groote Melanen geanalyseerd. Er kan worden geconcludeerd dat de afname in de totaal fosfor en blauwalgen chlorofyl-a concentraties in 2016 duiden op een vermindering in eutrofiering na de maatregelen. De algengemeenschap is op te delen in twee verschillende clusters vóór de maatregelen en een derde cluster ná de maatregelen. De indicatoren van de clusters vóór de maatregelen hebben een hogere tolerantie voor totaal fosfaat concentraties wat overeenkomt met de vermindering in eutrofiering. Hoewel de situatie is verbeterd, wijst de dominantie van blauwalgen echter nog steeds op eutrofe omstandigheden. We hebben geen informatie beschikbaar over de mogelijke oorzaak van de verandering in algengemeenschap tussen 2008 en 2011, maar mogelijk is deze verschuiving gerelateerd aan de weersomstandigheden. Doordat de verandering niet rechtlijnig is, komt de verbetering niet goed naar voren in de trendanalyse met de Principal Response Curve methode. Fytoplankton heeft echter een zeer korte levensduur waardoor algen bloeien zeer variabel kunnen zijn over tijd. Zeer frequente metingen van (blauwalgen) chlorofyl-a concentraties geven mogelijk efficiënter inzicht in de maat van algen bloeien en daarmee eutrofiëring over tijd dan moment opnames van de fytoplanktongemeenschap in plassen en meren. Een nadeel is echter dat met het gebruik van chlorofyl-a concentraties niet naar het effect van eutrofiëring op hogere planten, andere algen (benthisch) en dieren gekeken wordt. Deze andere organismen kunnen tevens als indicator dienen voor langere termijn processen, waarvoor fytoplankton minder geschikt is. 


\section{$1 \quad$ Inleiding}

Een van de doelen van de Kennisimpuls waterkwaliteit (KIWK) is het kwantificeren van de effectiviteit van lokale maatregelen in verschillende watertypen op verschillende organismegroepen. In dit document wordt de effectiviteit van een pakket van nutriënt reducerende maatregelen op de algenrespons in de Groote Melanen geanalyseerd.

De Groote Melanen is een in een woonwijk gelegen stadsven van 0,05 km² groot met veen- en zandbodem (KRW watertype M11; Figuur 1). In de periode van februari 2015-juni 2016 zijn zeer diverse maatregelen uitgevoerd ten behoeve van de waterkwaliteit en het terugdringen van blauwalgenoverlast. Deze maatregelen bestonden uit:

- $\quad$ het wegvangen van vissen (brasem en karpers)

- het baggeren van de sliblaag

- het herinrichten van de oever

- de aanleg van een omleidingssloot

- $\quad$ het afdekken van de waterbodem met zand en Phoslock,

- $\quad$ het toedienen van Phoslock + poly aluminium chloride (PAC)

- het aanbrengen van water- en oeverplanten

A

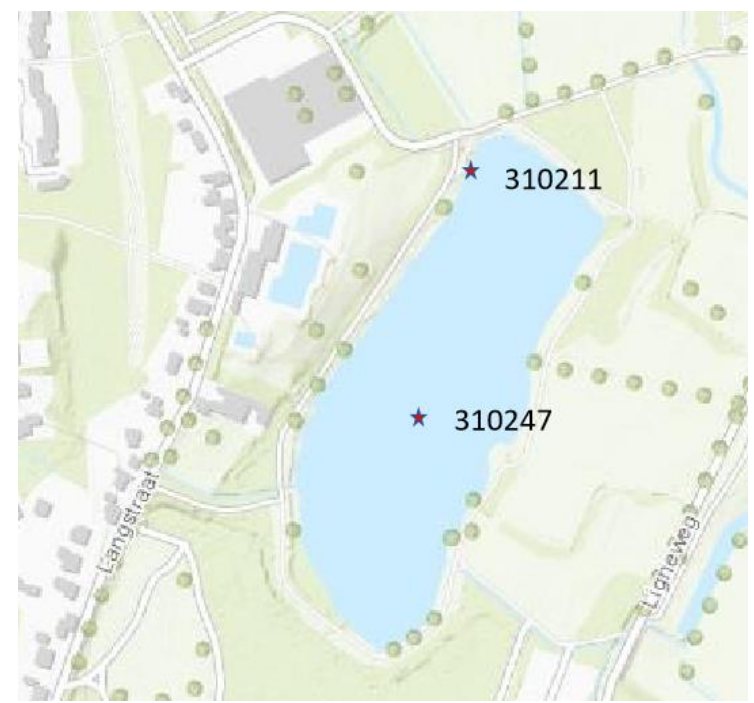

C

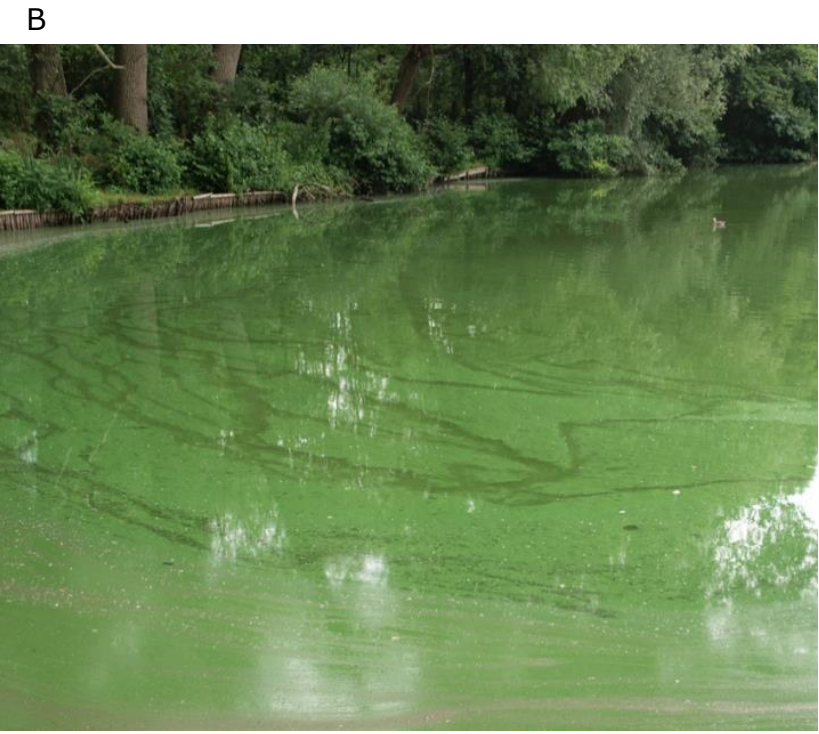

D
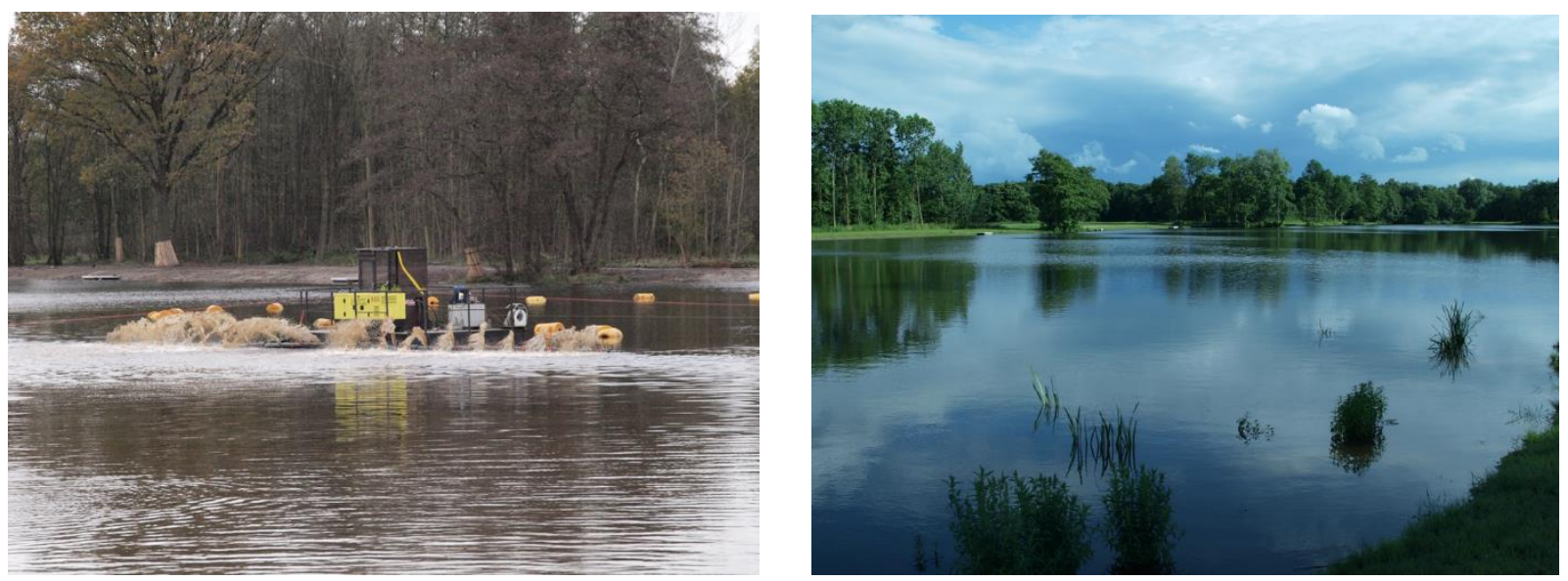

Figuur 1: A) Kaart van de Groote Melanen met algenmonsterpunten. De paarse sterren geven de locaties aan waar de algen zijn bemonsterd. B) Foto blauwalgenbloei vóór uitvoering verbetermaatregelen in de Groote Melanen, 13 juli 2010. C) Foto uitvoering van een van de verbetermaatregelen (bezanding), 20 november 2015, D) Foto kort na de afronding van de uitvoering van verbetermaatregelen in de Groote Melanen, 25 juni 2016. (Bron: Guido Waajen - Waterschap de Brabantse Delta). 


\section{Materiaal en methoden}

\subsection{Metingen}

De fytoplankton is sinds 2004 afwisselend over twee locaties in de stadsvijver bemonsterd (Figuur 1; Tabel 1; data afkomstig van Waterschap de Brabantse Delta). Per jaar zijn er 3-5 monsters genomen tussen juni en september en een beperkt aantal in de overige maanden (Tabel 2). In 2011 zijn beide locaties bemonsterd. Voor de vergelijkbaarbaarheid zijn in deze analyse alleen de monsters tussen juni en september meegenomen. De monsterlocaties zijn samengevoegd voor de analyse.

Tabel 1: Overzicht van de algenmonsterlocaties.

\begin{tabular}{llll}
\hline Naam & Code & Coördinaten & Metingen \\
\hline De Groote Melanen & 310211 & $51.52174,4.28923$ & $2004,2005,2008,2011,2014,2017$ \\
De Groote Melanen & 310247 & $51.52008,4.28868$ & $2011,2016,2018,2019$ \\
\hline
\end{tabular}

Tabel 2: Overzicht van het aantal monsters dat per maand is genomen over de verschillende jaren per meetlocatie en het aantal jaren dat iedere maand is bemonsterd.

\begin{tabular}{|c|c|c|c|c|c|c|c|c|c|c|c|c|c|}
\hline \multirow[b]{2}{*}{ Code } & \multirow[b]{2}{*}{ Jaar } & \multicolumn{12}{|c|}{ Maanden } \\
\hline & & 1 & 2 & 3 & 4 & 5 & 6 & 7 & 8 & 9 & 10 & 11 & 12 \\
\hline \multirow[t]{6}{*}{310211} & 2004 & & & 1 & 1 & & 2 & & 2 & 1 & 1 & & \\
\hline & 2005 & & & 1 & 1 & 1 & 1 & & 2 & 1 & & 1 & \\
\hline & 2008 & & & 1 & 1 & 1 & 1 & 1 & 1 & 2 & & & \\
\hline & 2011 & & & 1 & & 2 & 1 & & 1 & 2 & 1 & & \\
\hline & 2014 & & 1 & 1 & 1 & 1 & 1 & 1 & 1 & 1 & 1 & & \\
\hline & 2017 & & & & & 2 & 1 & 1 & 1 & 1 & & & \\
\hline \multirow[t]{4}{*}{310247} & 2011 & 1 & 1 & 1 & & 1 & 1 & & 1 & 1 & 1 & 1 & 1 \\
\hline & 2016 & & & & & & 1 & & 2 & 1 & & & \\
\hline & 2018 & & 1 & & & & & 1 & 1 & 1 & & & \\
\hline & 2019 & & & & & & 1 & 1 & 1 & 1 & & & \\
\hline \multicolumn{2}{|c|}{$\begin{array}{c}\text { Aantal jaren } \\
\text { bemonsterd }\end{array}$} & 1 & 3 & 5 & 4 & 6 & 9 & 5 & 10 & 10 & 4 & 2 & 1 \\
\hline
\end{tabular}

\subsection{Taxonomische afstemming}

De taxonomische lijsten, afkomstig uit verschillende jaren en van verschillende locaties, laten verschillen zien in taxonomische niveaus (Figuur 2A). Voor de analyse is een eenduidig gegevensbestand noodzakelijk. Daarom is voor de analyse de oorspronkelijke data taxonomisch afgestemd op basis van frequentie van voorkomen in de monsters en totale abundantie. Alle variëteiten zijn op soortniveau meegenomen. Indien een genus op een paar uitzonderingen na was gedetermineerd tot op soortniveau, is het genus verwijderd en zijn de soorten gehandhaafd. Indien de frequentie waarmee het genus of lager taxonomisch niveau voorkomt echter hoog was, is de data geaggregeerd op dat niveau. Bij de Chroococcales zijn naast de soorten ook de gehele groep Chroococcales meegenomen. De overige hogere taxonomische niveaus zijn verwijderd. Behalve voor de monstername op 29-06-2016 is maximaal $25 \%$ van de gegevens verwijderd (Figuur 2B).

\subsection{Data-analyse}

$\mathrm{Er}$ is eerst een gemiddelde abundantie per taxa per jaar berekend, waarna de gemiddelde abundantie is gestandaardiseerd naar een relatief aandeel per jaar. De gemiddelde relatieve abundantie is daarna $\log _{10}(x+1)$ getransformeerd om het effect van hoge dichtheden te verminderen en de rol van laagabundante soorten te vergroten. Allereerst hebben we de monsters puntsgewijs geclusterd volgens de $k$ means clustering methode. Het optimale aantal clusters is gekozen doormiddel van de silhouet analyse (Kassambara 2017). Per cluster hebben we de indicatorsoorten bepaald op basis van de getrouwheid en de relatieve abundantie binnen de groep (Dufrêne \& Legendre 1997). We zijn hier uitgegaan van indicatorsoorten met $p<0.05$. De indicatiewaarde geeft aan in hoeverre een taxon gerelateerd is aan een bepaald cluster. De indicatorsoorten hebben we vergeleken met de optimumcurves van de 
fytoplanktongenera volgens de Plankton trophic index (Phillips et al. 2012). Daarna hebben we de data doormiddel van een Principale-ComponentenAnalyse (PCA) geplot om de patronen in de algengemeenschap tussen de jaren weer te geven.

Vervolgens hebben we de data ook geanalyseerd volgens de 'Principal Response Curve (PRC)' methode (Van den Brink \& ter Braak, 1999; zie Box 1 voor uitgebreide uitleg). Deze methode biedt de mogelijkheid om veranderingen in de gemeenschap bij verschillende maatregelen (zogenoemde 'treatments') uit te zetten tegen de tijd. Dit resulteert in een grafiek met de tijd op de $x$-as en de verandering in de gemeenschap (zogenoemde 'canonical coefficient $C_{d t}$ ') ten opzichte van de mediaan van de gemeenschap voor de uitvoering van de herstelmaatregelen in de periode 2004 - 2014 op de y-as. Er zijn te weinig datapunten om vervolgens een 'changepoint analysis' toe te passen, dus hebben we de grafiek 'op het oog' geïnterpreteerd. Ieder taxon heeft een gewicht (zogenoemde 'species weight $b_{k}$ ') gekregen, wat aangeeft in welke mate het taxon het patroon van de respons volgt. Taxa met een positief gewicht volgen de verandering, taxa met een negatief gewicht vertonen een tegenovergestelde respons en taxa met een gewicht van bijna nul vertonen geen respons of een respons die niet gerelateerd is aan het patroon dat in het diagram wordt getoond. Alle analyses zijn gedaan in R (versie 3.6.3) met softwarepakketten vegan (Oksanen et al. 2019) en factoextra (Kassambara \& Mundt 2020).

A

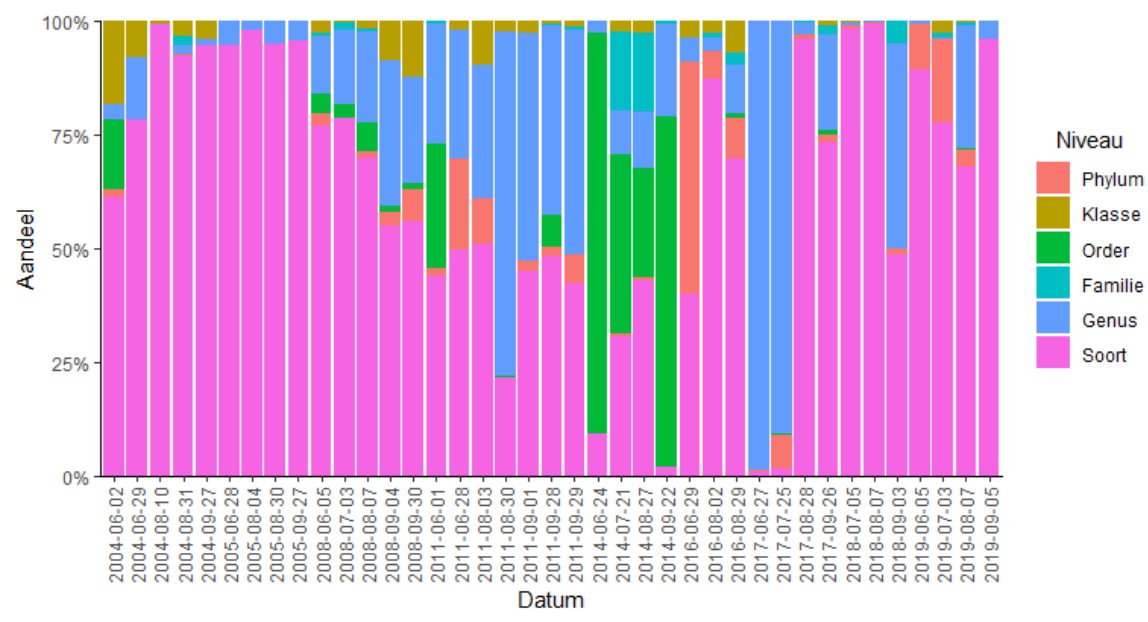

B

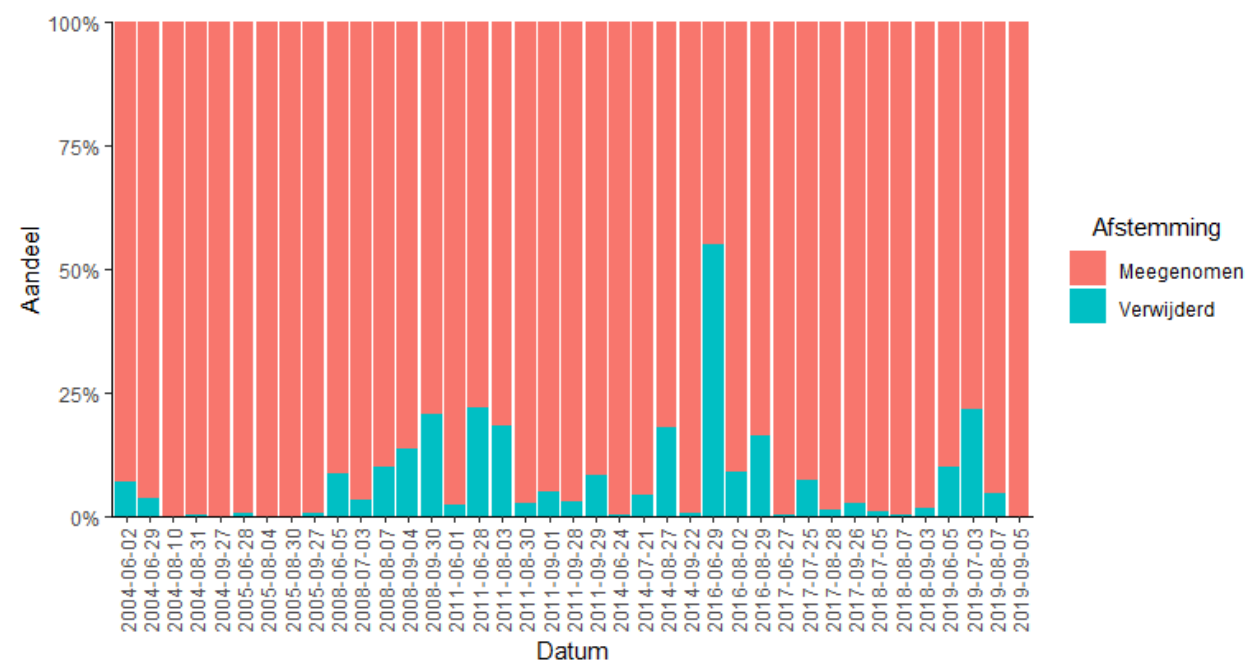

Figuur 2: A) Aandeel algencellen dat op verschillende taxonomische niveaus is gedetermineerd. B) Aandeel cellen dat door de afstemming is verwijderd. 
Box 1: Uitleg bij de grafiek van de 'Principal Response Curve' (PRC) analyse
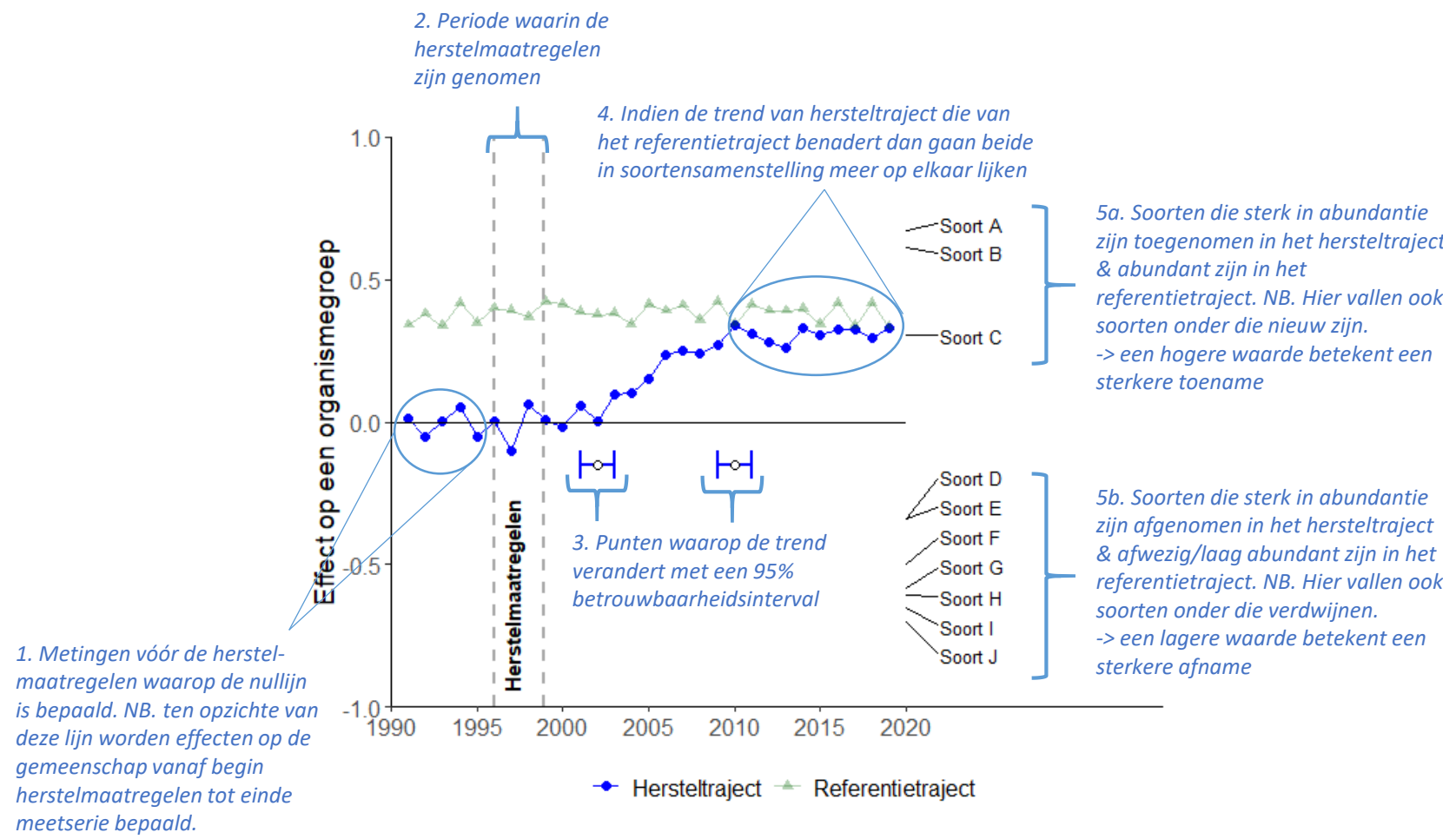

De bovenstaande figuur laat een hypothetisch voorbeeld zien van de uitkomst van de 'Principal Response Curve' analyse waarmee de resultaten grafisch inzichtelijk worden gemaakt. Het voorbeeld volgt een zogenaamd BACI-ontwerp met jaarlijkse metingen vóór (Before) en ná ( $\underline{A} f t e r)$ het nemen van de herstelmaatregelen in een referentietraject met de gewenste situatie (dit wordt de Control, genoemd en kan bijvoorbeeld een natuurgebied bovenstrooms zijn) en met jaarlijkse metingen vóór (Before) en ná (ㅅfter) in het hersteltraject, het traject waar de maatregelen zijn genomen (Impact). In plaats van een referentietraject kan de Control ook bestaan uit een traject dat vergelijkbaar is met het hersteltraject, maar waar geen maatregelen zijn genomen. In dat geval zou de lijn rond de nullijn moeten lopen omdat die situatie bijna gelijk is aan die in het hersteltraject voor het nemen van de maatregelen.

In de grafiek staat tijd op de $x$-as en de (eventuele) verandering in de gemeenschap (zogenoemde 'canonical coefficient $\left.C_{\mathrm{dt}}{ }^{\prime}\right)$ op de $y$-as. De verandering in de gemeenschap wordt uitgezet tegen de mediaan van de gemeenschap vóór de herstelmaatregelen, de zogehete nullijn (het traject aangeduid door tekstblok 1). Om deze nullijn goed te definiëren is het belangrijk dat er voldoende meetjaren beschikbaar zijn. De periode waarin de herstelmaatregelen zijn genomen wordt in de grafiek aangegeven met twee verticale grijze stippellijnen, in dit geval tussen 1996 en 1999 (aangeduid met teksblok 2). In dit voorbeeld hebben de maatregelen een effect gehad op de samenstelling van de gemeenschap, aangezien de $\mathrm{C}_{\mathrm{dt}}$ Score van het hersteltraject van de nullijn gaat afbewegen na de uitvoering van het herstel. Dit betekent hoe hoger de $C_{d t}$ score wordt des te groter is het effect van de maatregel(en). Als er geen verandering optreedt dan blijft de $C_{d t}$ score van het hersteltraject rondt de nullijn schommelen. Indien er voldoende data beschikbaar is (minimaal 10 meetjaren), kan met een zogenaamde 'changepoint analysis' worden aangegeven of en wanneer verandering in de trend heeft plaatsgevonden (aangeduid met tekstblok 3). In het bovenstaande voorbeeld laten deze punten met het $95 \%$ betrouwbaarheidsinterval (de horizontale blauwe lijnstukken) zien dat de gemeenschap tussen 2002 en 2010 is veranderd. We zien ook dat de lijn van het hersteltraject de lijn van het referentietraject gaat benaderen (aangeduid met tekstblok 4). Dit betekent dat de herstelmaatregelen een positief effect hebben gehad op deze gemeenschap. Aan de rechterkant van de grafiek is af te lezen welke soorten het sterkst aan deze verandering hebben bijgedragen (zogenaamde 'species weight $b_{k}{ }^{\prime}$ ). Soorten die zijn toegenomen in het hersteltraject en abundant zijn in het referentietraject hebben een positieve score (aangeduid met tekstblok $5 a$ ) en soorten die zijn afgenomen in het hersteltraject en minder abundant/afwezig zijn in het referentietraject hebben een negatieve score (aangeduid met tekstblok $5 b)$.

De analyse kan in principe ook worden gedaan met alleen een BA- of CI-ontwerp. Bij een BA-ontwerp is het echter niet uit te sluiten of de veranderingen door de herstelmaatregelen worden veroorzaakt of in het hele gebied hebben plaatsgevonden. Bij een CI design moet de nullijn worden bepaald op basis van de mediaan van de Control (de waarnemingen in het referentie- of controletraject). Als de Control in milieu-omstandigheden (typologisch) niet goed vergelijkbaar is met de situatie in het herstel van voor de maatregelen dan zullen alleen deze verschillen worden weergegeven in de grafiek. Ook is niet uit te sluiten dat de veranderingen al voor de herstelmaatregelen waren begonnen. 


\section{Resultaten}

\subsection{Algemene trends}

Sinds de maatregelen in 2016 is een duidelijke afname in de totaal fosfor (Figuur 3) en blauwalgen chlorofyl-a concentraties gemeten (Figuur 4). De concentratie blauwalgen cellen in de fytoplanktonmonsters laten dit patroon echter niet zien (Figuur 5A). Er is een grote variatie tussen de metingen (doordat bijvoorbeeld kolonies zijn bemonsterd), waardoor is gekozen om de analyse uit te voeren op basis van relatieve abundantie. De algengemeenschap wordt over de gehele meetperiode gedomineerd door blauwalgen (Cyanophyta) afgewisseld met groenalgen (Chlorophyta) (Figuur 5B). Blauwalgen domineren vaak onder eutrofe omstandigheden, met name in meren met een chlorofyl-a $>10$ $\mu \mathrm{g} / \mathrm{L}$ (Phillips et al. 2003, Ptacnik et al. 2008). Hoewel de chlorofyl-a in de Groote Melanen sterk is afgenomen, is deze ook na de maatregelen nog $>10 \mu \mathrm{g} / \mathrm{L}$ (Supplement Tabel S1).

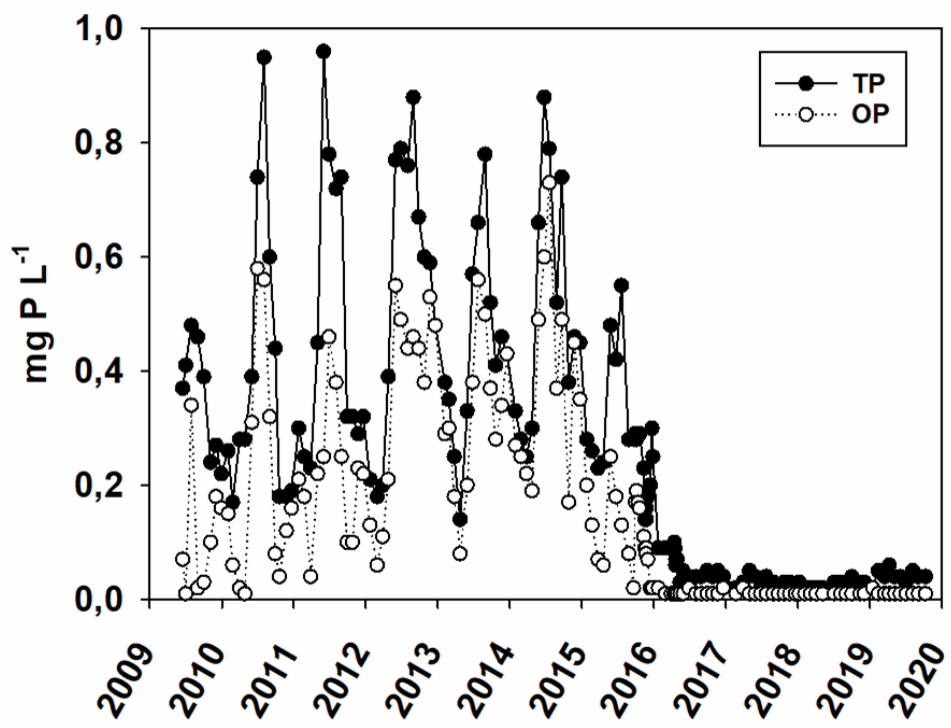

Figuur 3: Totaal fosfor (TP) en otho-fosfaat (OP) tussen juni 2009 en oktober 2019. De herstelmaatregelen zijn uitgevoerd in de periode van februari 2015-juni 2016.

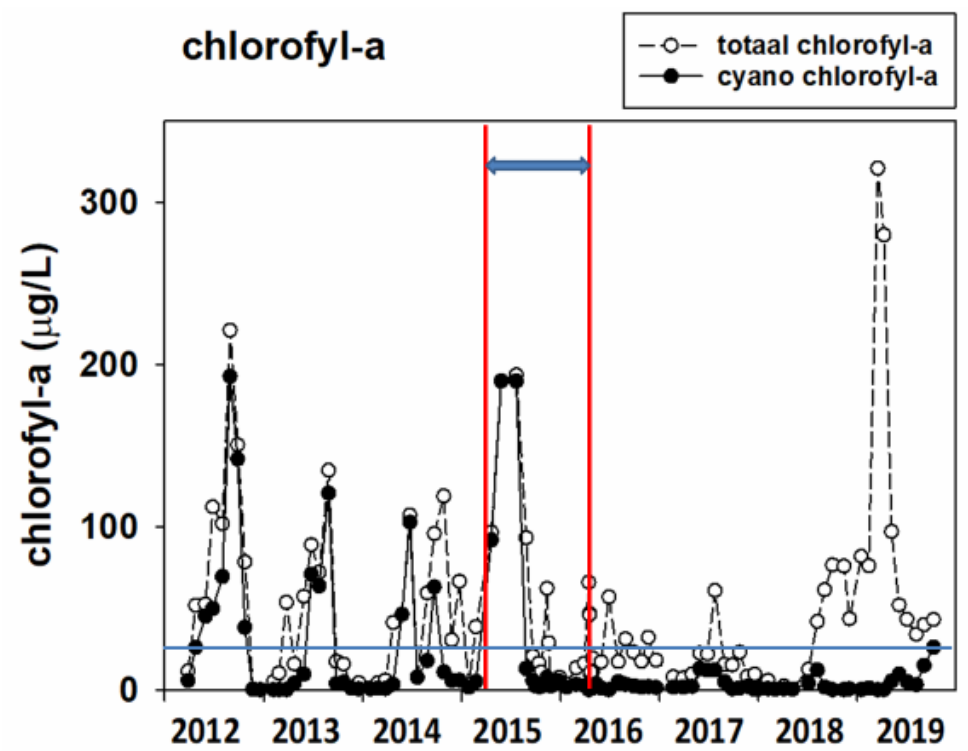

Figuur 4: Concentraties totaal en blauwalgen-chlorofyl-a tussen 2012 en 2019. De herstelmaatregelen zijn uitgevoerd in de periode van februari 2015-juni 2016 (aangegeven met rode lijnen). 
A
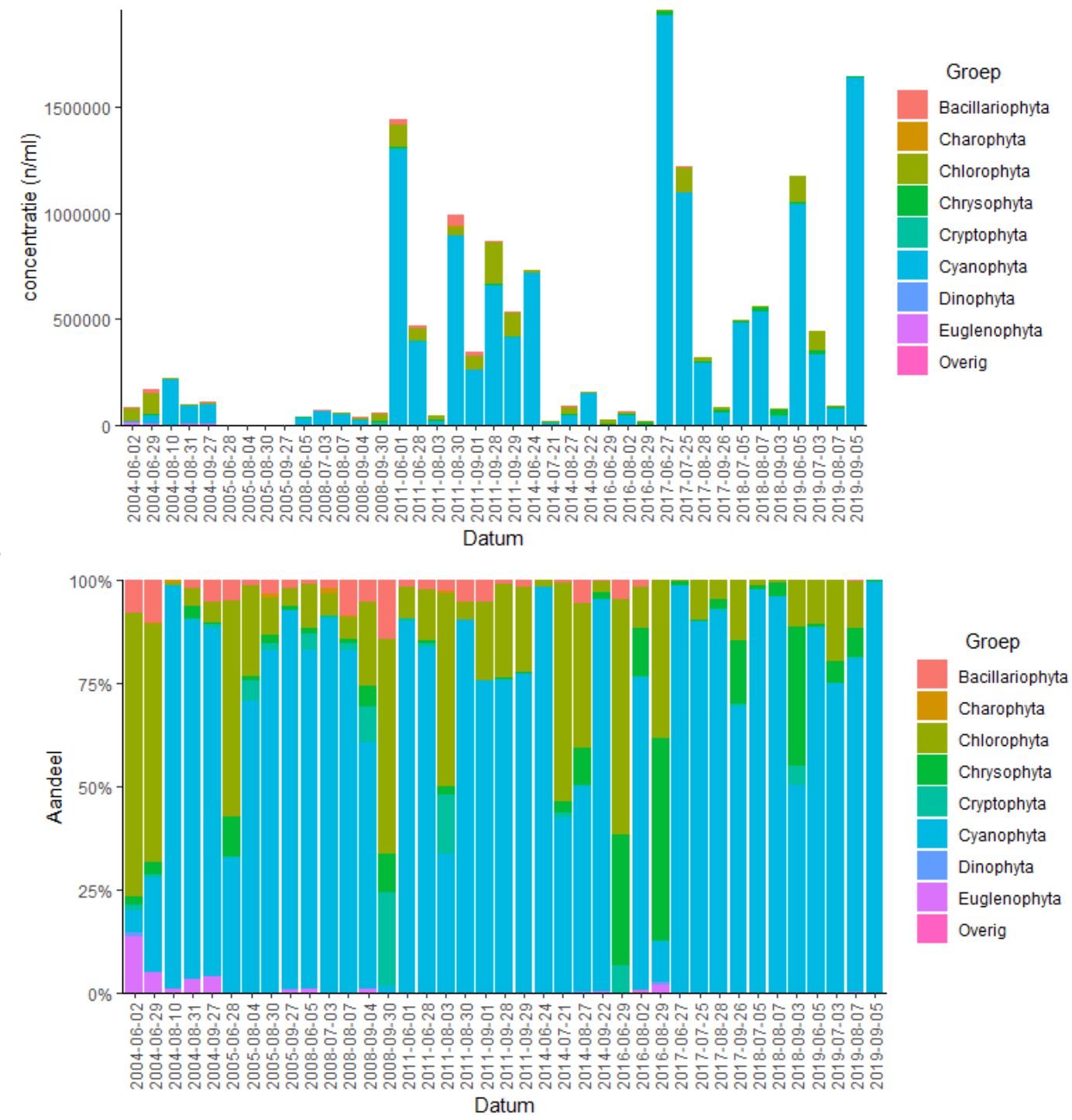

Figuur 5: Voorkomen verschillende groepen in A) absolute concentraties en B) aandeel van het monster 


\subsection{PCA ordinatie en cluster analyse}

De clustering van de data op een hoger taxonomisch niveau laat een verdeling in drie groepen over de tijd zien (Tabel 2). Cluster 1 bestaat uit de jaren 2004, 2005 en 2008, cluster 2 uit de jaren 2011 en 2014 en cluster 3 uit de jaren na de maatregelen 2016-2019. In 2011 zijn allebei de meetlocaties bemonsterd en behoren tot hetzelfde cluster. De PCA ordinatie laat hetzelfde patroon tussen de jaren zien als de cluster analyse (Figuur 6). In Tabel 3 staan de taxa die specifiek gerelateerd zijn aan de drie clusters. De tolerantie voor totaal $P$ van indicatoren van de eerste twee clusters is gemiddeld ( \pm sd) hoger (cluster 1: $46 \pm 32 \mu \mathrm{g}$ $\mathrm{TP} / \mathrm{L}$, cluster 2: $42 \pm 22 \mu \mathrm{g} \mathrm{TP} / \mathrm{L}$ ) dan het laatste cluster na de maatregelen (cluster 3: $13 \pm 3 \mu \mathrm{g}$ TP/ L). Planktothrix agardhii is een indicator voor cluster 1 en genera Microcystis voor cluster 2. Bloeien van deze 'negatieve' blauwalgen zijn kenmerkend voor eutrofe stadsvijvers in Nederland, waarbij Planktothrix meer wordt geassocieerd met gemengd water en Microcystis kenmerkend is voor thermische stratificatie (Waajen et al. 2014). We hebben geen informatie beschikbaar over de mogelijke oorzaak van de verandering in algengemeenschap tussen 2008 en 2011. De verlaging van de tolerantie voor totaal $P$ van de indicatoren in de monsters na 2016 duidt op een vermindering in de eutrofiëring nadat de herstelmaatregelen zijn genomen.

Tabel 2: Overzicht van clustering van de jaren.

\begin{tabular}{llccc}
\hline Locatie code & Jaar & Cluster 1 & Cluster 2 & Cluster 3 \\
\hline 310211 & 2004 & $\mathrm{x}$ & & \\
310211 & 2005 & $\mathrm{x}$ & & \\
310211 & 2008 & $\mathrm{x}$ & & \\
310247 & 2011 & & $\mathrm{x}$ & \\
310211 & 2011 & & $\mathrm{x}$ & \\
310211 & 2014 & $\mathrm{x}$ & \\
310247 & 2016 & & & $\mathrm{x}$ \\
310211 & 2017 & & & $\mathrm{x}$ \\
310247 & 2018 & & & $\mathrm{x}$ \\
310247 & 2019 & & & \\
\hline
\end{tabular}

Tabel 3: Overzicht van taxa die indicatief zijn voor de groepen uit tabel 2. De Indval-waarde (indicatiewaarde) geeft aan in hoeverre een taxon gerelateerd is aan een bepaald cluster, de $p$-waarde geeft de waarschijnlijkheid van het verkrijgen van een even hoge indicatorwaarden als waargenomen over de gespecificeerde iteraties en de frequentie geeft het voorkomen in de verschillende monsters in een cluster. De indicatorsoorten hebben we vergeleken met de optimumcurves van de fytoplanktongenera volgens de Plankton trophic index (Phillips et al. 2012). n.v.t. betekent dat (op dit taxonomisch niveau) geen informatie beschikbaar is. De twee meetlocaties in 2011 zijn samengevoegd.

\begin{tabular}{l|l|lll|lll}
\hline Taxa & cluster & $\begin{array}{l}\text { Indval- } \\
\text { waarde }\end{array}$ & p- & Faarde & Freque & \multicolumn{3}{|c}{ Tolerantie TP $(\mu \mathrm{g} / \mathrm{L})$} \\
& & & & & Gemiddeld & Minimum & Maximum \\
\hline Dictyosphaerium & 1 & 1.00 & 0.012 & 3 & 21 & 11 & 41 \\
Limnothrix & 1 & 1.00 & 0.014 & 3 & 51 & 37 & 71 \\
Planktothrix agardhii & 1 & 1.00 & 0.016 & 4 & 50 & 28 & 88 \\
Actinastrum & 1 & 0.97 & 0.018 & 4 & 109 & 70 & 172 \\
Goniochloris mutica & 1 & 0.96 & 0.039 & 5 & 73 & 39 & 135 \\
Closterium limneticum & 1 & 0.93 & 0.009 & 6 & 32 & 19 & 54 \\
Chlamydomonas & 1 & 0.84 & 0.032 & 8 & 22 & 12 & 41 \\
Monoraphidium & 1 & 0.83 & 0.039 & 6 & 12 & 7 & 22 \\
Contortum & & & & & & & \\
Microcystis & 2 & 1.00 & 0.028 & 2 & 64 & 38 & 108 \\
Pseudostaurastrum & 2 & 1.00 & 0.023 & 2 & 41 & 25 & 66 \\
Woronichinia & 2 & 1.00 & 0.026 & 2 & 20 & 13 & 31 \\
Chroococcales & 2 & 0.99 & 0.02 & 4 & n.v.t. & n.v.t. & n.v.t. \\
Chrysococcus rufescens & 3 & 1.00 & 0.007 & 4 & 15 & 8 & 25 \\
Kephyrion & 3 & 1.00 & 0.01 & 4 & 9 & 6 & 15 \\
Chrysochromulina parva & 3 & 0.93 & 0.003 & 7 & 15 & 8 & 25 \\
Cyanogranis & 3 & 0.69 & 0.011 & 7 & n.v.t. & n.v.t. & n.v.t. \\
\hline
\end{tabular}




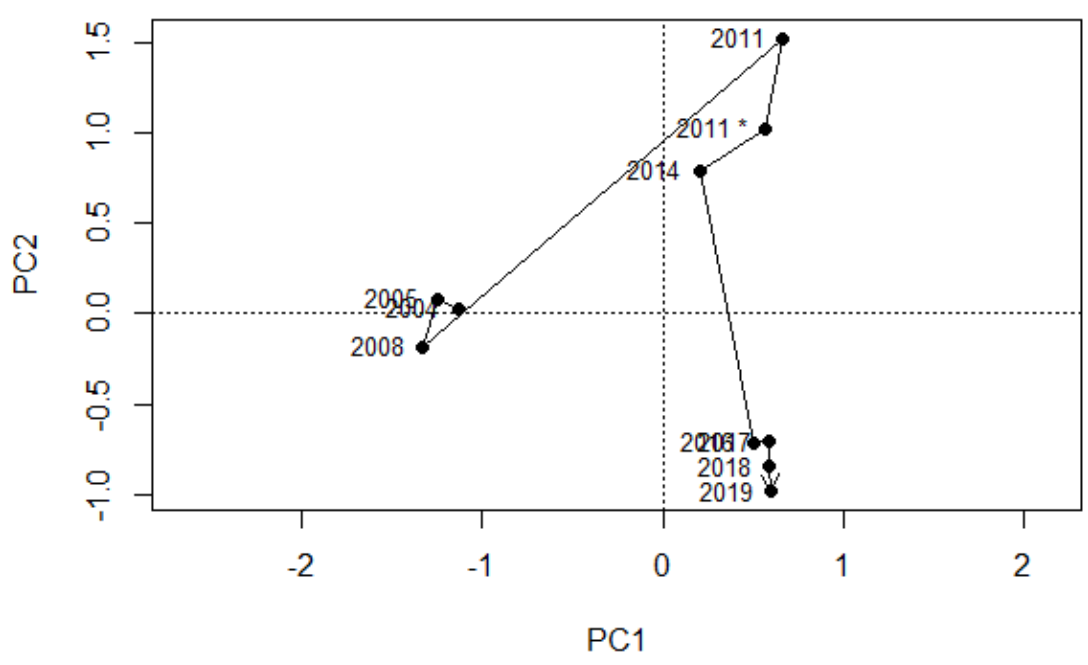

Figuur 6: Ordinatie (PCA) van de gemiddelde algengemeenschap per jaar door de tijd aangegeven met een pijl. 2011 met * is genomen op locatie 310211 en zonder * op locatie 310247.

\subsection{PRC analyse}

Wanneer we, gebruik makend van een PRC-analyse, de algengemeenschap uitzetten in de tijd tegen de mediaan van de gemeenschap in de periode 2004 - 2014 is de verdeling in drie clusters niet langer zichtbaar (Figuur 7). Deze analyse methode lijkt minder geschikt wanneer de verandering niet rechtlijnig is, maar in feite over twee assen plaatsvindt (Figuur 6).

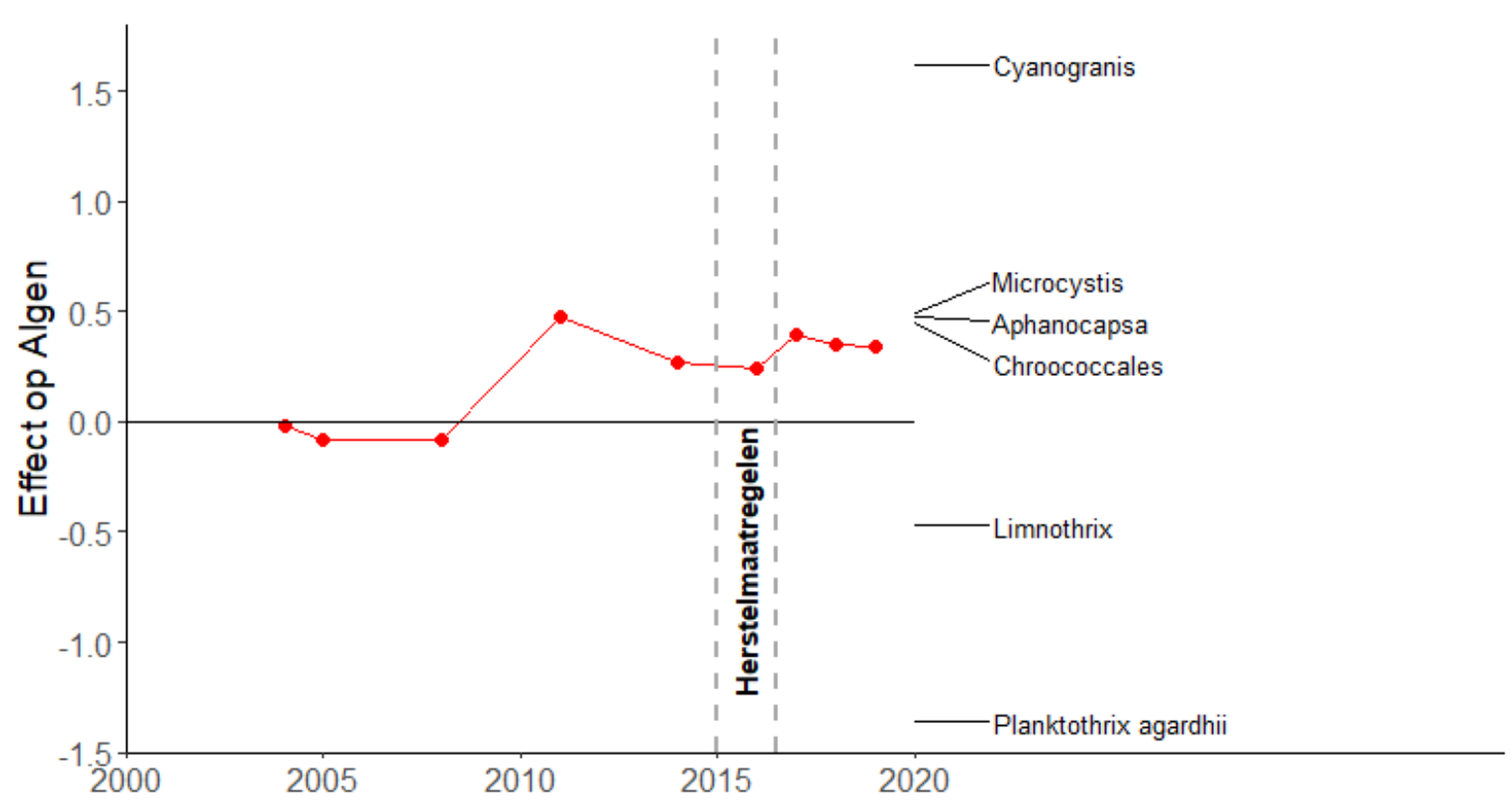

Figuur 7: Verandering in de algengemeenschap in de Groote Melanen ten opzichte van de mediaan van de gemeenschap in de toestand voorafgaand aan het nemen van de herstelmaatregelen in de periode 2004-2014 en gepresenteerd volgens de zogeheten Principal Response Curve. De soortgewichten in het rechterdeel van het diagram vertegenwoordigen de affiniteit van elk taxon met de respons weergegeven in het diagram. Voor de duidelijkheid zijn alleen de afnemende taxa met een gewicht $<-0.4$ en de toenemende taxa met een gewicht $>0.4$ weergegeven. 


\section{Conclusies}

De afname in de totaal fosfor en blauwalgen chlorofyl-a concentraties in 2016 duiden op een vermindering in eutrofiëring na de maatregelen. De algengemeenschap is op te delen in twee verschillende clusters vóór de maatregelen en een derde cluster ná de maatregelen. De indicatoren van de clusters vóór de maatregelen hebben een hogere tolerantie voor totaal fosfor concentraties, de eerste periode (2004-2008) voor een meer met een gemengde waterkolom en de tweede periode (2011-2014) voor een meer met een gestratificeerde waterkolom. We hebben geen informatie beschikbaar over de mogelijke oorzaak van de verandering in algengemeenschap tussen 2008 en 2011, maar een overgang van een gemengde waterkolom naar een gestratificeerde kan met de weersomstandigheden samenhangen. De indicatoren voor de derde periode, 2016-2019, duiden t.o.v. de twee eerdere perioden op een vermindering in eutrofiëring. Hoewel de situatie is verbeterd, wijst de dominantie van blauwalgen echter nog steeds op eutrofe omstandigheden.

Doordat de verandering niet rechtlijnig is, komt de verbetering niet goed naar voren in de trendanalyse met de Principal Response Curve methode. Fytoplankton heeft een zeer korte levensduur waardoor algen bloeien zeer variabel kunnen zijn over tijd. Het is aan te bevelen om in plaats van moment opnames van de fytoplanktongemeenschap zeer frequente metingen van (blauwalgen) chlorofyl-a concentraties in plassen en meren uit te voeren om mogelijk efficiënter inzicht in de maat van algen bloeien en daarmee eutrofiëring over tijd te krijgen. Een nadeel is echter dat met het gebruik van chlorofyl-a concentraties niet naar het effect van eutrofiëring op hogere planten, andere algen (benthisch) en dieren gekeken wordt. Het is daarom ook aan te bevelen deze andere organismen mee te nemen in de monitoring als indicator voor langere termijn processen, waarvoor fytoplankton minder geschikt is. 


\section{Literatuur}

Dufrêne, M., \& Legendre, P. (1997). Species assemblages and indicator species: the need for a flexible asymmetrical approach. Ecological monographs, 67(3), 345-366.

Kassambara, A. \& Mundt, F. (2020). factoextra: Extract and Visualize the Results of Multivariate Data Analyses. R package version 1.0.7. https://CRAN.R-project.org/package=factoextra

Kassambara, A. (2017). Practical guide to cluster analysis in R: Unsupervised machine learning (Vol. 1). Sthda.

Oksanen, J., Blanchet, F.G., Friendly, M., Kindt, R., Legendre, P., McGlinn, D., Minchin, P. R., O'Hara, R. B., Simpson G. L., Solymos, P., Henry, M., Stevens, H., Szoecs, E., \& Wagner, H. (2019). vegan: Community Ecology Package. $\mathrm{R}$ package version 2.5-6. https://CRAN.Rproject.org/package $=$ vegan

Phillips, G., Lyche-Solheim, A., Skjelbred, B., Mischke, U., Drakare, S., Free, G., ... \& Carvalho, L. (2013). A phytoplankton trophic index to assess the status of lakes for the Water Framework Directive. Hydrobiologia, 704(1), 75-95.

Ptacnik, R., Lepistö, L., Willén, E., Brettum, P., Andersen, T., Rekolainen, S., .. \& Carvalho, L. (2008). Quantitative responses of lake phytoplankton to eutrophication in Northern Europe. Aquatic Ecology, 42(2), 227-236.

Van den Brink, P. J., \& Braak, C. J. T. (1999). Principal response curves: Analysis of time-dependent multivariate responses of biological community to stress. Environmental Toxicology and Chemistry: An International Journal, 18(2), 138-148.

Waajen, G. W., Faassen, E. J., \& Lürling, M. (2014). Eutrophic urban ponds suffer from cyanobacterial blooms: Dutch examples. Environmental Science and Pollution Research, 21(16), 9983-9994.

Zeileis, A., Kleiber, C., Kraemer, W., \& Hornik, K. (2003). Testing and Dating of Structural Changes in Practice. Computational Statistics \& Data Analysis, 44, 109-123. 


\section{Supplement}

Tabel S1: Mediaanwaarden en gemiddelden van de concentraties van totaal fosfor $\left(T P, m g P L^{-1}\right)$, orthofosfaat (OP, $\left.m g P L^{-1}\right)$, totaal stikstof $\left(T N, m g ~ N L^{-1}\right)$, ammoniak $\left(N_{3}, m g ~ N L^{-1}\right)$, ammonium $\left(\mathrm{NH}_{4}^{+}, \mathrm{mg} \mathrm{N}^{-1}\right.$ $\left.\mathrm{L}^{-1}\right)$, nitriet $\left(\mathrm{NO}_{2}^{-}, \mathrm{mg} \mathrm{N} \mathrm{L^{-1 }}\right)$, nitraat $\left(\mathrm{NO}_{3}^{-}, \mathrm{mg} \mathrm{N} \mathrm{L}^{-1}\right)$, stikstof Kjeldahl $\left(\mathrm{N}-\mathrm{Kj}, \mathrm{mg} \mathrm{N} \mathrm{L}^{-1}\right)$, chlorofyl-a (Chla, $\mu g \mathrm{~L}^{-1}$; bepaald met FluoroProbe als som van 4 chlorofyl-a fracties, en spectrofotometrisch bepaald), blauwalgen chlorofyl-a (cyano chl-a, $\mu \mathrm{g} \mathrm{L^{-1 }}$; bepaald met FluoroProbe), zuurstof $\left(\mathrm{O}_{2}, \mathrm{mg} \mathrm{L} \mathrm{L}^{-1}\right)$, totaal lanthaan ( $\left.T L a, \mu g L^{-1}\right)$, filtreerbaar lanthaan ( $\left.F L a, \mu g L^{-1}\right)$, totaal aluminium (TAl, $\mu g L^{-1}$ ), filtreerbaar aluminium ( $\mathrm{FAl}, \mu \mathrm{g} \mathrm{\textrm {L } ^ { - 1 }}$ ), chloride $\left(\mathrm{Cl}^{-}, \mathrm{mg} \mathrm{L}^{-1}\right)$ en sulfaat $\left(\mathrm{SO}_{4}{ }^{2-}, \mathrm{mg} \mathrm{L}^{-1}\right)$ en de gemiddelde waarden van doorzicht ( $m$ ), troebelheid (FTU) en $\mathrm{pH}$. Weergegeven zijn de resultaten van de metingen in de hele onderzoeksperiode vóór de maatregelen (17 juni 2009 tot en met 27 januari 2015) en in de gehele onderzoeksperiode na de maatregelen (29 juni 2016 tot en met 9 juli 2020), tenzij anders vermeld. Tussen haakjes is bij de gemiddelden de standaarddeviatie gegeven met $n=a a n t a l$ waarnemingen. Meetpunt 310247. * en vet gedrukt betekent significant verschil voor en na maatregelen $(P<0,05)$.

\begin{tabular}{|c|c|c|c|c|}
\hline & \multicolumn{2}{|c|}{ voor maatregelen } & \multicolumn{2}{|c|}{ na maatregelen } \\
\hline & mediaan & gemiddelde & mediaan & gemiddelde \\
\hline $\mathrm{TP}\left(\mathrm{mg} \mathrm{P} \mathrm{L}^{-1}\right)^{*}$ & 0,39 & $0,45(0,22 ; n=69)$ & 0,03 & $0,03(0,01 ; n=48)$ \\
\hline $\mathrm{OP}\left(\mathrm{mg} \mathrm{P} \mathrm{L}^{-1}\right)^{*}$ & 0,25 & $0,27(0,18 ; n=69)$ & 0,01 & $0,01(0,00 ; n=48)$ \\
\hline $\mathrm{TN}\left(\mathrm{mg} \mathrm{N} \mathrm{L}^{-1}\right)^{*}$ & 3,50 & $3,68(1,11 ; n=69)$ & 1,30 & $1,31(0,18 ; n=48)$ \\
\hline $\mathrm{NH}_{3}\left(\mathrm{mg} \mathrm{N} \mathrm{L}^{-1}\right)^{*}$ & 0,01 & $0,01(0,00 ; n=65)$ & 0,00 & $0,00(0,00 ; n=48)$ \\
\hline $\mathrm{NH}_{4}^{+}\left(\mathrm{mg} \mathrm{N} \mathrm{L}^{-1}\right)^{*}$ & 0,20 & $0,38(0,40, n=69)$ & 0,05 & $0,07(0,05 ; n=48)$ \\
\hline $\mathrm{NO}_{2}^{-}\left(\mathrm{mg} \mathrm{N} \mathrm{L}^{-1}\right)^{*}$ & 0,02 & $0,03(0,03 ; n=69)$ & 0,01 & $0,01(0,00 ; n=48)$ \\
\hline $\mathrm{NO}_{3}^{-}\left(\mathrm{mg} \mathrm{N} \mathrm{L}^{-1}\right)^{*}$ & 0,20 & $0,80(0,98 ; n=69)$ & 0,06 & $0,11(0,11 ; n=48)$ \\
\hline $\mathrm{N}-\mathrm{Kj}\left(\mathrm{mg} \mathrm{N} \mathrm{L}^{-1}\right)^{*}$ & 2,70 & $2,89(0,80 ; n=69)$ & 1,20 & $1,20(0,24 ; n=48)$ \\
\hline Chl-a fluoroprobe $\left(\mu \mathrm{g} \mathrm{L}^{-1}\right)^{1)}$ & 46,3 & $52,8(53,0 ; n=35)$ & 23,1 & $43,2(59,4 ; n=49)$ \\
\hline Chl-a spectrofotometrisch $\left(\mu \mathrm{g} \mathrm{L}^{-1}\right)^{*}$ & 46,0 & $75,7(79,4 ; n=69)$ & 17,0 & $19,7(17,1 ; n=48)$ \\
\hline Cyano chl-a $\left(\mu \mathrm{g} \mathrm{L}^{-1}\right)^{*}$ & 5,8 & $31,9(46,9 ; n=35)$ & 1,9 & $4,6(5,7 ; n=48)$ \\
\hline $\mathrm{O}_{2}\left(\mathrm{mg} \mathrm{L}^{-1}\right)^{*}$ & 9,25 & $9,06(2,87 ; n=70)$ & 10,30 & $10,34(1,74 ; n=48)$ \\
\hline TLa $\left(\mu \mathrm{g} \mathrm{L}^{-1}\right)^{* 2)}$ & 0,20 & $0,16(0,05 ; n=13)$ & 45,70 & $53,12(30,05 ; n=41)$ \\
\hline FLa $\left.\left(\mu \mathrm{g} \mathrm{L}^{-1}\right) * 2\right)$ & 0,04 & $0,05(0,03 ; n=13)$ & 4,72 & $6,06(3,90 ; n=41)$ \\
\hline TAl $\left.\left(\mu \mathrm{g} \mathrm{L}^{-1}\right)^{* 3}\right)$ & 93,00 & $92,23(22,29 ; n=13)$ & 240,00 & $312,69(262,16 ; n=49)$ \\
\hline FAl $\left(\mu \mathrm{g} \mathrm{L}^{-1}\right)^{3)}$ & 16,00 & $23,85(14,96 ; n=13)$ & 17,00 & $18,48(9,90 ; n=48)$ \\
\hline $\mathrm{Cl}^{-}\left(\mathrm{mg} \mathrm{L}^{-1}\right)^{4)}$ & 38,00 & $39,12(10,33 ; n=65)$ & 38,90 & $39,26(4,70 ; n=48)$ \\
\hline $\mathrm{SO}_{4}^{2-}\left(\mathrm{mg} \mathrm{L}^{-1}\right)^{* 4)}$ & 22,00 & $22,20(6,97 ; n=65)$ & 16,90 & $17,16(2,08 ; n=48)$ \\
\hline Doorzicht (m) & 0,60 & $0,63(0,28 ; n=70)$ & 0,60 & $0,66(0,29 ; n=48)$ \\
\hline Troebelheid (FTU) $\left.{ }^{5}\right)$ & 10,00 & $23,53(28,71 ; n=61)$ & 10,50 & $11,48(5,52 ; n=48)$ \\
\hline $\mathrm{pH}^{*}$ & 7,60 & $7,80(0,71 ; n=70)$ & 8,20 & $8,30(0,22 ; n=48)$ \\
\hline
\end{tabular}

